\title{
Integrated Municipal Solid Waste Management System (IMSWMS)
}

\author{
Magripa Nleya ${ }^{1}$, Lovemore Gunda $^{2}$, Zvirevo Chisadza $^{3}$, and Dr. Mercy Manyuchi ${ }^{3}$
}

\begin{abstract}
Rapid population growth, industrialization, urbanization and technology trends have led to a sharp increase in solid waste generation. Some municipalities are still using the conventional approach to solid waste management leading to solid waste becoming a sight everywhere. It is important to monitor solid waste collection and record the information pertaining to collection time, area and other related data from a central location. For this purpose, an Integrated Municipal Solid Waste Management System (IMSWMS) is presented and discussed in this paper. The system ensures solid waste reduction through proper collection monitoring, waste intelligence initiatives and environmental education. It is an embedded system incorporating global positioning system (GPS), radio frequency identification (RFID) technology, which is interfaced with a microcontroller and a web based graphical user interface (GUI) that can be accessed from anywhere. The web based GUI allows real time interaction of the central office with waste collection processes and residents.
\end{abstract}

Keywords---Environment management, radio frequency identification, solid waste management, waste intelligence.

\section{INTRODUCTION}

$\mathrm{R}$ APID increase in population and industrialization has led to an increase in solid waste generation resulting in increased pests and pollution. Daily generated waste in urban centers of Zimbabwe in 2011 was estimated to be at 1.65 million tones [1]. Zimbabwean newspaper, The Herald [2], reported in May 2013 that Zimbabwe produced an average of 2.5 million tones of solid waste (household and industrial combined) and that waste collection by local authorities had dropped from $80 \%$ of total waste across different authorities in the mid 1990s to as low as $30 \%$ in some large and small towns. The Environmental Management Regulations of Zimbabwe prohibit the disposal of waste in undesignated areas [3].

Magripa Nleya ${ }^{1}$, Lovemore Gunda ${ }^{2}$, and Zvirevo Chisadza ${ }^{3}$ are with the National University of Science and Technology, Bulawayo, Zimbabwe.

Dr. Mercy Manyuchi ${ }^{4}$ is with the Harare Institute of Technology, Harare, Zimbabwe.
The existing conventional waste collection and management approach has the following problems:

- Lack of proper monitoring system for tracking all activities related to solid waste management, such as lack of information about the collection time and area [2].

- Slow response to urgent cases such as waste collection vehicles accident or breakdown and to clients' complains about uncollected waste [1].

- There is no link between the municipality and the community.

- The municipality's solid waste management processes are not linked anyhow to the residents.

- Lack of waste collection vehicles, or their inefficient utilization and unauthorized use [4].

The solution is the Integrated Municipal Solid Waste Management System (IMSWMS). This paper is a presentation of the design and implementation of a centralised solid waste management system (IMSWMS). The system aims to reduce solid waste while at the same time enhancing utilization of solid waste as a resource. It remotely monitors and controls the collection of municipal solid waste giving real time feedback, linking the municipality with the community while at the same time putting in place realization of waste as a resource. Fig. 1 shows the Integrated Municipal Solid Waste Management System layout. It shows how the solid waste collection processes and residents are linked to the central office.

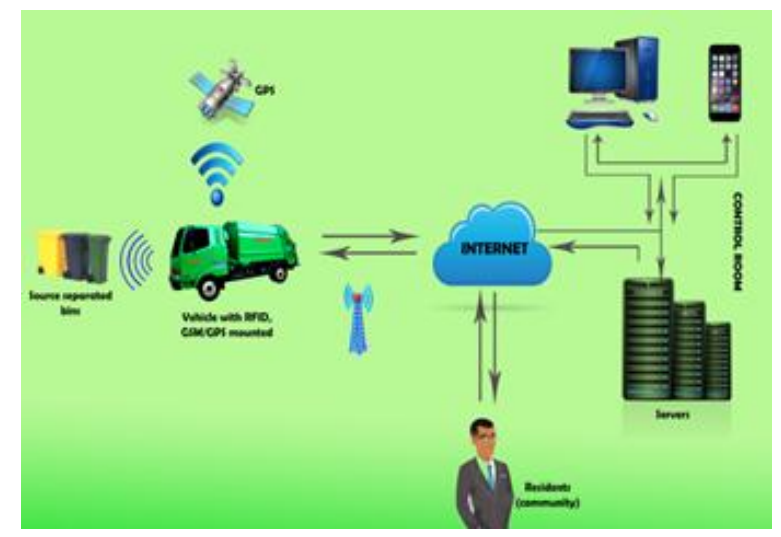

Fig. 1 Integrated Municipal Solid Waste Management System layout 
The literature related to solid waste management is presented in Section II below focusing on the background on solid waste management and some existing solid waste management systems.

\section{LITERATURE REVIEW}

Solid waste consists of everyday items that are used and then thrown away, such as product packaging, grass clippings, furniture, clothing, bottles, food scraps, newspapers, appliances, paint, and batteries. It is commonly known as trash or garbage and mainly comes from homes, schools, hospitals, and businesses [5]. This has become a common sight not only in Zimbabwe but globally. Causes of waste generation include urbanization, population growth, industrialization, economic development [6], non-cooperating community and lack of environmental education on solid waste management [7]. Changes in technology trends can also lead to an increase in waste generation. Solid waste if not managed or collected leads to many problems such as:

- $\quad$ spread of diseases[7]

- deterioration in agriculture activities

- $\quad$ land, water and air pollution [6]

- deterioration in tourism industry

- development of hideouts for thieves and thugs[5]

- blockage of drainage system and surface water contamination [5]

- $\quad$ risk of fire [6]

- destruction of ecosystem and properties

- loss of livestock due to consumption of plastics.

According to Zaman [8], the world's population grows by more than 200000 each day. Currently, half the world's population lives in urban areas and almost all regions will be predominantly urban by the middle of the twentieth century. According to Mudzengerere [5], 50\% of solid wastes generated in Bulawayo City, Zimbabwe are plastics as shown in Fig. 2.This clearly shows that solid waste is a major concern and its management needs to be given priority.

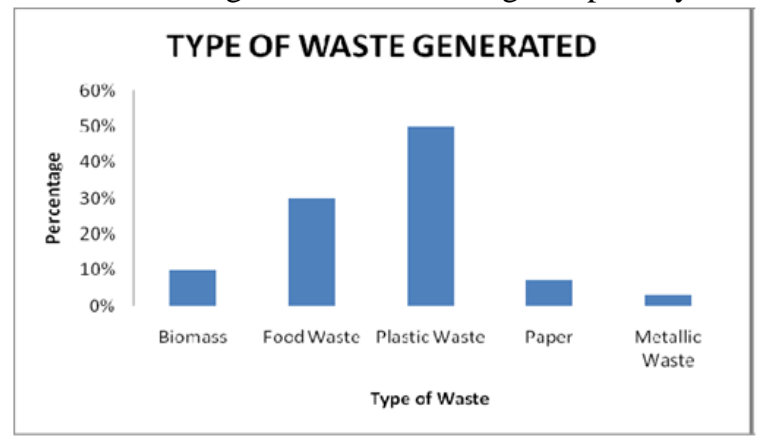

Fig.2 Types of solid waste in Bulawayo City, Zimbabwe. [5]

In Zimbabwe rapid population growth, urbanization, industrialization and changes in living and technology trends have led to a sharp rise in solid waste generation [6]. Fig. 3 shows some ways used for waste management in the city of Bulawayo.

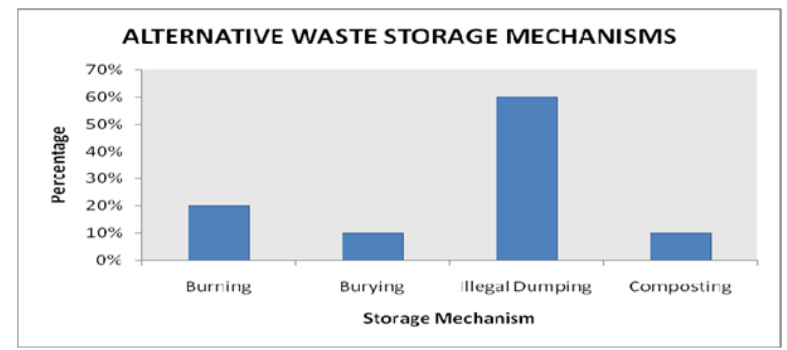

Fig. 3 Waste management of Bulawayo city residents [6]

It is evident from Fig. 3 that illegal dumping is the major waste disposal method used in Bulawayo. This is an unmonitored and unsafe way of solid waste management and has serious negative impacts on the environment and pose health hazards to the community. The 5Rs of solid waste management [7] give a hierarchy in which any solid waste management plan must comply. The main aim is to extract materials and to generate the minimum amount of waste. Fig. 4 below illustrates elements of the 5R's and their priorities.
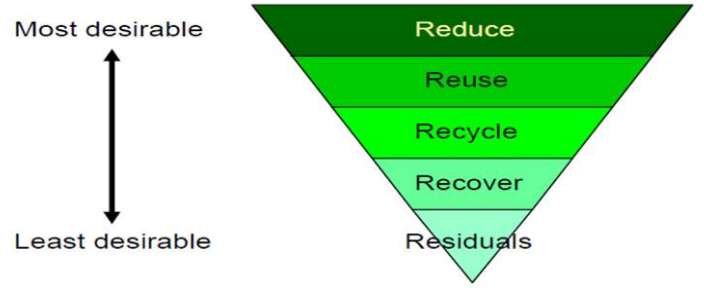

Fig. 4 Elements of 5R's hierarchy [7]

The 5R's are explicitly explained as follows:

- Reduce implies that residents should make wise choices that reduce amount of waste.

- Reuse is using a material again in the same function or using it for a new function.

- Recycling is the reprocessing of materials into new materials. This decreases consumption of new raw materials and saves on the energy requirements.

- Recover applies to the recovery of either materials or energy from a mixed waste stream.

- Residuals refer to the management of materials which remain after the previous 4R's have been applied. This is often in the form of landfill disposal but beneficial uses of residual material can sometimes be available [7].

Solid Waste Management is the systematic control of generation, reduction, collection, storage, transport and disposal of municipal solid waste [8]. The process of solid waste management is large and complex, involving many attention demanding critical areas which makes it often exposed to mismanagement. Solid waste management strategies differ from country to country due to differences in waste generation rates, amount of resources and public reception on environmental education. In Zimbabwe solid waste management is under the Local authorities (municipalities) which are distributed in respective cities and districts.

According to the research [8], various solid waste management strategies have been deployed in various areas 
across the world. Some of the existing systems areas described below.

Efficient garbage disposal management in metropolitan cities using Vehicular Ad hoc Networks (VANET) consists of dustbins, wireless sensor circuitry, road side units (RSU), and the waste removal vehicles [9]. VANET uses vehicles as mobile nodes in a metropolitan area network and turns them into a wireless router or node [10]. This system employs source separation and waste is collected as soon as any waste receptacle is full. They are equipped with suitable low power sensor circuitry to detect the fullness and heaviness which sends a message to the nearest waste removal vehicle. Shortest path to a full waste receptacle is also deduced by the system. This system was implemented in Bangalore Metropolitan city in India. However such a system has fuel consumption, expensive initial setup and road damages as its problems.

Solid waste bin monitoring using zigbee [11] is based on collecting the waste from overflowing areas, which was implemented in Pune, India. Ultrasonic sensors placed on the waste receptacle lid sense the level of waste. When the level reaches a defined value, a signal is sent through zigbee technology to the ARM microcontroller board placed in the Central Office. The Central Office identifies the place and area and the information is conveyed to the driver of the waste removal vehicle through short message service (SMS). Deployment of such a system might have road damages and fuel consumption as its problems.

A Web based GIS waste disposal management system of Nigeria uses a database driven web page with Geographic Information System (GIS). The spatial distribution of waste bins provides the geographical information of all the waste collection tanks in any ward [12]. A web based GIS only concentrates on the spatial distribution of waste receptacles as a guide to waste collection processes. It tends to neglect other crucial pillars of solid waste management such as source separation and collection monitoring. Solid waste management in Damaturu, Yobe State, Nigeria [7] concentrates on wastes generated mainly from residential, commercial and institutional land uses. Waste collection bins are placed at strategic locations identified by the agency and termed as high waste generating points with wheeled plastic waste bins, metal waste bins and constructed waste bunkers. The contents of these bins are disposed at a location about six kilometres away from the generating points. Spatial data on waste distribution is collected using GIS and GPS. The system makes sure that waste is collected by providing many waste receptacles especially at high waste generating points. This on its own contributes to solid waste reduction especially when coupled together with source separation and proper collection monitoring.

The above mentioned systems show the importance of having a monitored waste management system. Information discussed above has aided the design and implementation of an Integrated Municipal Solid Waste Management System (IMSWMS) which is a centralized solid waste management system. IMSWMS reduces solid waste while contributing to environmental sustainability through utilization of solid waste as a resource. The system presented in this paper achieves this using GPS and RFID technology coupled with GSM services. Various techniques and processes leading to solid waste reduction have been integrated to come up with a comprehensive and effective solid waste management strategy. The system integrates software, hardware and web services in an effort to reduce solid waste.

\section{INTEGRATED MUNICIPAL SOLID WASTE MANAGEMENT SYSTEM DESIGN}

The waste management systems described in literature clearly shows the importance of having an integrated approach to waste management. There is need for consistent collection and monitoring of waste collection. Working with schedules has proven inefficient because waste generation depends on events and days. An efficient system ensures action on demand so that only critical situations are attended. This section is a description of the design and implementation of the system. The hardware design is presented first followed by the software design. The integrated system is presented last.

\section{A. Hardware design}

The hardware consists of Arduino Microcontroller Board, GPS module, Liquid Crystal Display (LCD) and an RFID reader mounted on the solid waste removal vehicle. RFID tags are mounted on waste receptacles such that when the waste removal vehicle reaches within the vicinity of the receptacles, the unique tags are read by the RFID reader. These tags are used to uniquely identify a waste receptacle by its residential area and household number. After three RFID scans the system extracts the GPS coordinates (longitude and latitude) from the GPS module mounted on the vehicle. All this information including date and time is send to the central office via GSM. The GPS is used to find the exact location of the waste removal vehicle at a particular time [9]. To aid the curbside collection, the RFID reader is mounted at the back of the vehicle while tags are mounted at the base of waste receptacles. This makes sure that tags will be read only when waste is emptied (collected) into the vehicle to avoid a situation where tags can be read when the vehicle just passes by. The Arduino acts as the brain of the system [13]. To program the microcontroller, Arduino $C$ language is used. The RFID ID-12LA is preferred for its seamless integration with the common $125 \mathrm{kHz}$ tags. In order to use the ID-12LA RFID reader with an Arduino Uno, an ID12 breakout is used to enhance connections between the reader and other components. Fig. 5 shows a breakout and RFID12 RFID reader interface with the Arduino. 


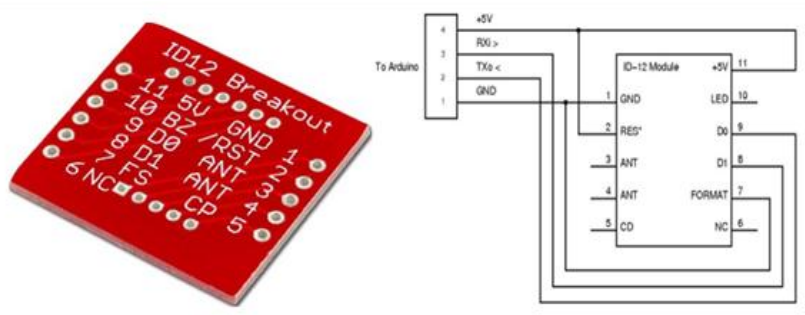

Fig. 5 ID12 Breakout and its Arduino pin interface

An Arduino 1.6.2 IDE is used as an editor to write the code that interfaces the RFID and the Arduino. The serial monitor is used for easy pretesting to show the results as tags are scanned. Using the unique characters obtained, each tag is assigned to a particular waste receptacle of a particular residential area. An Econet Subscriber Identity Module (SIM) card is inserted into the SIM908 GSM/GPS V1 development board. This helps in the wireless sending of information pertaining to solid waste collection. The tags are assigned names which represent waste receptacles of a particular residential area. A 16x2 Liquid Crystal Display (LCD) is used to display information such as residential area, house number and GPS latitude and longitude coordinates. Fig. 6 shows an LCD and the Arduino connection.

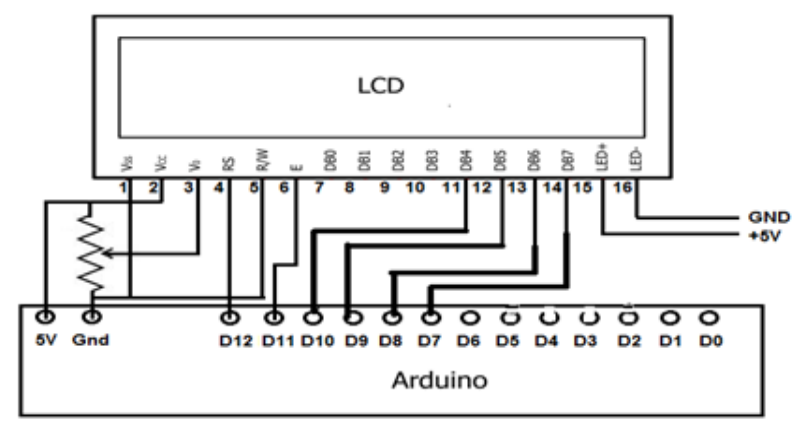

Fig. 6 LCD Arduino interfacing

To measure the amount of waste entering the landfill, a force resistive sensor is used. Figure 7 shows the connection of the force transducer to the Arduino board.

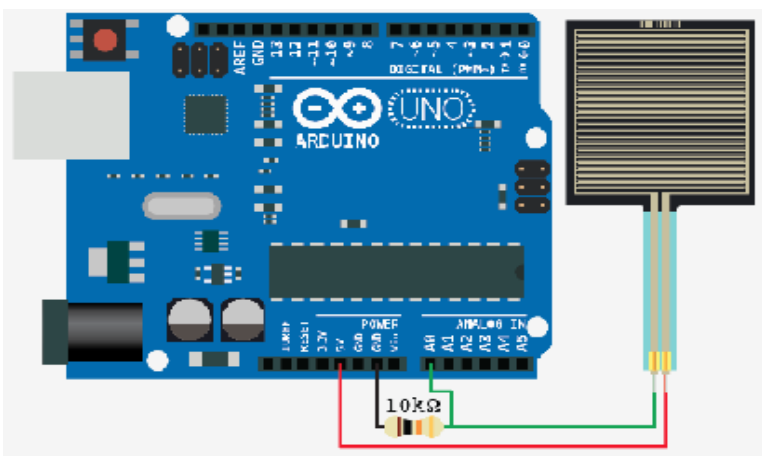

Fig. 7 Interfacing the force sensitive resistor with an Arduino Uno

The resistor based sensor is connected and calibrated using know values of mass. The results are shown in Table 1 and Fig 8.
TABLE 3.1

DIFFERENT MASSES WITH THEIR RESPECTIVE OUTPUT ADC OUTPUTS

\begin{tabular}{|l|l|}
\hline Mass $(\mathrm{kg})$ & Output value \\
\hline 0.5 & 50 \\
\hline 1.5 & 147 \\
\hline 2.5 & 252 \\
\hline 3.5 & 343 \\
\hline 4.5 & 457 \\
\hline 5.5 & 550 \\
\hline 6.5 & 639 \\
\hline 7.5 & 745 \\
\hline 8.5 & 854 \\
\hline 9.5 & 1000 \\
\hline
\end{tabular}

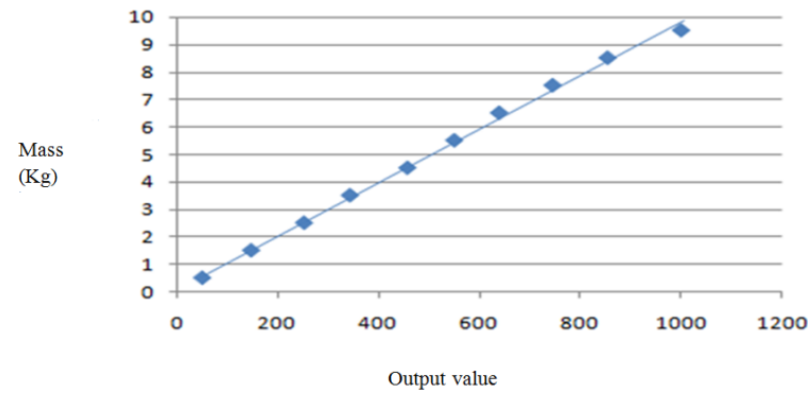

Fig 8 Graph of Output ADC value from force sensitive resistor against mass

When the force applied is increased its resistance increases. Resistance (R) is directly proportional to the voltage (V) so when the resistance increases the output voltage of the resistive force sensor also increases. Thus the output is between 0 and 1024 due to the scaled analogue voltage of 0 to 5V. From Figure 8, the gradient of the graph gives the constant $\mathrm{k}$ that can be used to convert the given output value to mass in kilograms.

\section{B. Software design}

An interactive website linking the municipality with the community enhances the centralization of solid waste management. Languages used for designing the website are PHP, HTML, JavaScript and JQuery. Cascading Style Sheets (CSS) is used to style the website. A MySQL database is used to store all the information. The website has five pages which are: Home, About-IMSWMS, Waste-Collection, Environmental-Education, Waste Intelligence and Contact us. Home page serves as a welcome to users of Integrated Municipal Solid Waste Management System. Login buttons shown in Fig. 9 are linked to other various pages. Fig 10 shows the collection scheduling interface.

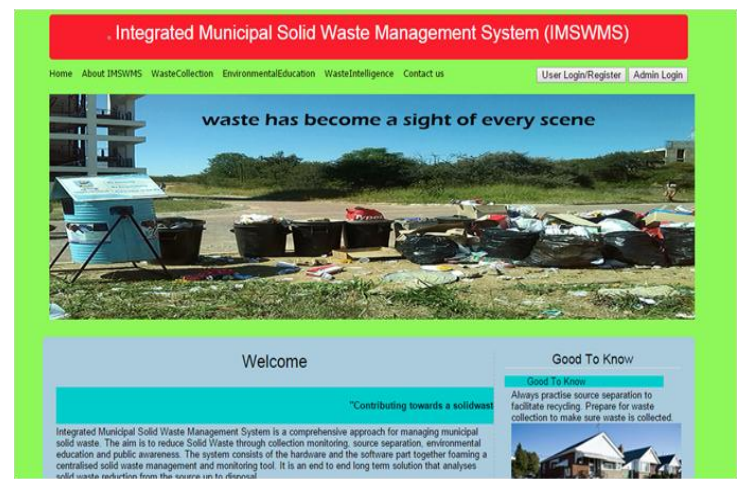

Fig. 9 The web based interface home page 


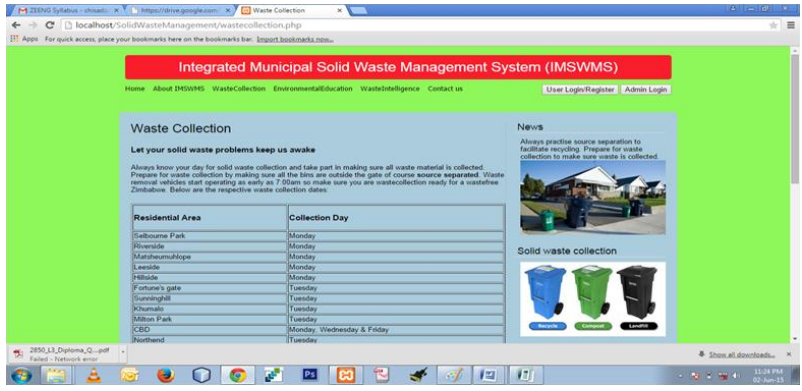

Fig 10 Waste collection scheduling page

The different interlinked pages on the web based interface show the required information by navigating from the home page. The operator at the central office uses the web based interface to monitor the waste collection as well as the collection vehicles. The software and the hardware are integrated to form a fully functional system.

\section{Integrated Municipal Solid Waste Management System}

More functionality is added to the system and the software and hardware are integrated to produce a complete system. Fig. 11 shows a block diagram of the system with the hardware mount on the waste removal vehicle and the software part at the central office side. Whatever will be happening on solid waste collection and its management will be communicated wirelessly and in real time to the control room (central office).

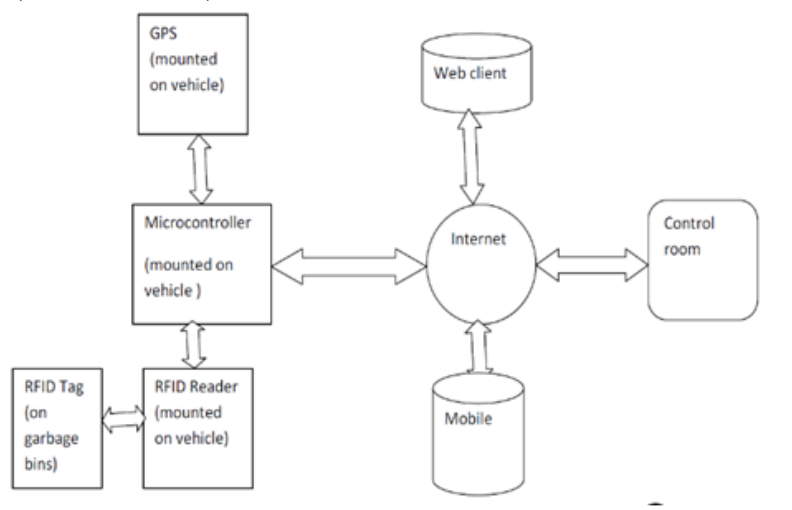

Fig. 11 Integrated Municipal Solid Waste Management System functional block diagram.

\section{RESULTS AND DISCUSSION}

The model of IMSWMS shown in Fig. 12 was tested practically and evaluated.

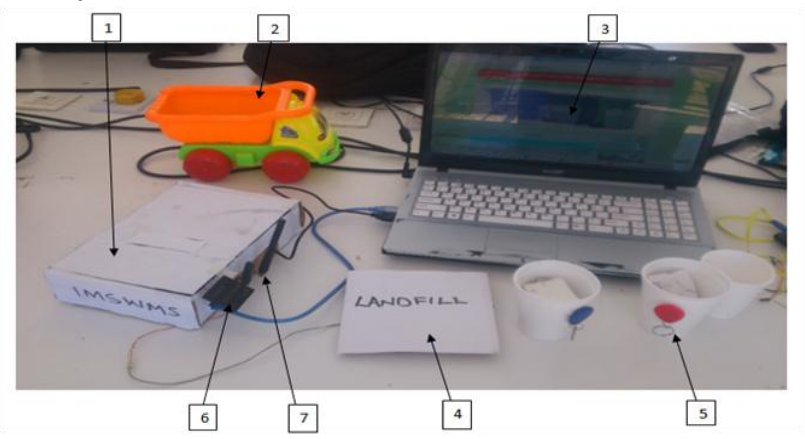

Fig. 12 Final IMSWMS model
The numbered components of the system are described as follows:

1. Black box containing GSM/GPS module, RFID and microcontroller,

2. Solid waste removal vehicle model

3. Central office website

4. Force sensitive sensor part of the circuit

5. Waste receptacles with tags

6. RFID reader

7. GSM GPS antennas

Through the use of the system, the following is achieved:

- Through source separation, more than $40 \%$ solid waste conversion into resources is achieved.

- Remote collection monitoring is achieved as the system scans different waste receptacles and remotely updates the central office database in real time.

- $\quad$ The GPS used enables the extraction of the exact location of the solid waste removal vehicle. Tracks followed by the vehicle are then formed on Google map by using saved GPS coordinates.

- Several waste intelligence initiatives such as source separation and green bin initiative are introduced by the system. This enables the realization and utilization of solid waste as a resource.

- The project contributes to environmental sustainability through environmental education and linking the municipality with the community that is provided by the interactive website.

- The amount of solid waste entering a landfill is measured through the use of a force sensitive resistor.

The objectives of ensuring waste collection monitoring, determining the location of waste removal vehicles and identifying the receptacles in an effort to reduce solid waste generation and accumulation were achieved

\section{RECOMMENDATIONS}

Several improvements can be done to the system to increase its efficiency:

- Incorporating an Ethernet shield will result in improvement in the sending of large volumes of data to the central office. This enhances even storage of these large volumes of data through the creation of virtualized platforms.

- Using tags that are embedded in waste receptacles on manufacturing.

- Using more sensitive force sensor or mini weighbridge for measuring the amount of solid waste entering the landfill.

- Using a Tiny GPS module will enhance formation of tracks followed by waste removal vehicles through its embedded different file integration capabilities.

- $\quad$ For an efficient practical implementation the system should be linked with the media for efficient environmental education.

- Local authorities should build recycling centers and waste to energy plants. Revenue from recycling and other 
waste intelligence measures can be used to further finance solid waste management practices.

- Advanced technologies such as wireless sensors should be used in modern day solid waste management. Such systems can be expensive on initial deployment but their long run benefits are important.

- Environmental societies should be formed at workplaces, academic institutions and/or at community level.

- Ways to incentivize residents on solid waste management should be improvised.

- Wheeled waste tanks or large waste receptacles with the capacity of up to one tone should be placed at overcrowding areas to assist existing small waste receptacles. These large waste tanks can have the mechanism by which they send a text message to the control room whenever they are full.

- Color sorting waste bags should be used to collect specific types of waste such as electronic components waste.

\section{CONCLUSION}

The municipal waste management system design and implementation has been presented. It has been observed that the management of waste needs an integrated approach which includes those who produce the waste, those who collect the waste as well as those with technological knowhow. The use of GPS, GSM and RFID simplifies the management of waste and improves environmental sustainability.

\section{REFERENCES}

[1] Zimbabwe Environmental Agency, "The role of community based organizations (CBOs) in waste management." The Herald, Zimbabwe, Feb. 11, 2015.

[2] S. Tsiko, "Recycling could be the answer." The Herald Zimbabwe, May $1,2013$.

[3] Environmental Management Agency, "Plastic Packaging and Plastic Bottles Regulation SI 98, 2010". Available online at http://www.ema.co.zw/index.php/2014-06-12-03-49-33/2014-06-12-2059-13/environmental-regulations/39-plastic-packaging-and-plasticbottles-regulation-si-98-2010.html. [Accessed Oct. 2014].

[4] J. Magwenzi, "A study of household waste management behaviors in Hatfield and Sunningdale in Harare Zimbabwe" ,MPhil Thesis, Bindura State University, Zimbabwe, March 2013.

[5] U. Zaman, S. Lehmann, "Challenges and Opportunities in Transforming a City into a "Zero Waste City", Multidisciplinary Digital Publishing Institute. pp 21, 74. Nov 2011. http://dx.doi.org/10.3390/challe2040073

[6] F. H. Mudzengerere and Average Chigwenya, "Waste management in Bulawayo City council in Zimbabwe", Journal of sustainable development in Africa, ,pp 6-7, 2012 .

[7] E. C. Makwara, S. Magudu, "Confronting the reckless gambling with people's health and lives: Urban Solid Waste Management in Zimbabwe", European Journal of Sustainable Development, Vol. 2(1), pp 67-98. 2013.

[8] M. Vancouver, "Strategy for updating the solid waste management plan", March 15, 2008. available online at : http://www.metrovancouver.org/services/solidwaste/SolidWastePublications, [Accessed Dec.12, 2014].

[9] F. Li and L. Wang, "Routing in Vehicular Adhoc Networks", IEEE Vehicular Technology Magazine, Vol 2(2), pp 12-22, June 2007. http://dx.doi.org/10.1109/MVT.2007.912927

[10] N. Kumar, C. Swamy, K. N. Nagadarshini, "Efficient Garbage Disposal Management in Metropolitan Cities Using VANETs" Journal of Clean EnergyTechnologies, Vol.2(3), pp 3-4, July 2014.
[11] K. Mahajan, J. S. Chitode, "Solid waste bin monitoring using zib-bee", Journal of Engineering Research and Application. Vol. 4(6), pp 161164. June 2014.

[12] P. Idowu, Emmanuel R. Adagunodo, Olapeju A. Esimai, and Tosin C. Olapade, (June 2012), "Development of A Web based GIS Waste Disposal Management System for Nigeria", International Journal of Information Engineering and Electronic Business, Vol 3(1), pp 40-48, June 2012. http://dx.doi.org/10.5815/ijieeb.2012.03.06

[13] Arduino Forum, "What is arduino", Available at; http://www.arduino.cc/en/Guide/Introduction, [Accessed Mar. 3, 2015]. 